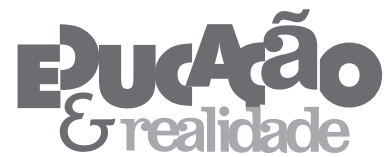

\section{O Trabalho de Professores/as em Um Espaço de Privação de Liberdade}

\author{
Maria Hermínia Lage Fernandes Laffin \\ Andréa Rettig Nakayama
}

RESUMO - O Trabalho de Professores/as em Um Espaço de Privação de Liberdade. O presente artigo apresenta uma pesquisa que teve como problemática as necessidades de formação continuada dos docentes que atuam na Escola Supletiva da Penitenciária, situada no Complexo Penitenciário do município de Florianópolis. A pesquisa evidenciou e neste artigo se apresentam as demandas de atuação dos/as docentes investigados, as quais não estão restritas às questões relacionadas diretamente ao modo de funcionamento dos espaços de privação de liberdade, mas sim a questões mais abrangentes relacionadas às particularidades do trabalho docente nesses espaços, às metodologias, modo de compreender os estudantes, a relação com os profissionais do complexo penitenciário e fundamentos da Educação de Jovens e Adultos.

Palavras-chave: Docência. Educação de Jovens e Adultos. Espaços de Privação de Liberdade.

ABSTRACT - The Work of Teachers in an Incarceration Space. The present paper presents a research work that had as its problematics the needs for continuing education of the teachers acting in the Penitentiary Supplementary School, sited in Florianópolis city Penitentiary Complex. The research shows evidence that the needs for continuing education of the teachers under investigation are not only restricted to the way the incarceration spaces work, but also to broader questions related to specificities of the educators working in those spaces, to their methodologies, their understanding of the students, the relationship with employees of the penitentiary complex, and to the foundations of Education for Youngsters and Adults.

Keywords: Teaching. Education of Youngsters and Adults. Incarceration Spaces.

Educação \& Realidade, Porto Alegre, v. 38, n. 1, p. 155-178, jan./mar. 2013.

Disponível em: <http://www.ufrgs.br/edu_realidade> 
Este artigo analisa as demandas de atuação dos docentes que atuam na Escola Supletiva da Penitenciária, situada no Complexo Penitenciário do município de Florianópolis, questão que emerge da pesquisa de mestrado - O trabalho de professores/as em "um espaço de privação de liberdade": necessidades ${ }^{1}$ de formação continuad ${ }^{2}$-, tendo como sujeitos de pesquisa quatorze professores/as da educação escolar de jovens e adultos em espaços de privação de liberdade, na Escola Supletiva ${ }^{3}$ da Penitenciária de Florianópolis. Optou-se por pesquisar o contexto da Escola Supletiva da Penitenciária de Florianópolis e justifica-se essa escolha por três fatores: o primeiro, por ser a mais antiga instituição penal da região de Florianópolis e do estado; o segundo motivo deve-se ao fato de ser a maior e mais antiga escola inserida em unidades prisionais e de internação do estado de Santa Catarina; e o terceiro, pelo fato de que a pesquisadora/autora da dissertação já ter atuado como docente nessa instituição de ensino.

Desse modo, a problematização se fez a partir da premissa de que, se a docência na Educação de Jovens e Adultos é marcada por especificidades, cabe pensar suas particularidades e os sujeitos em situação de privação de liberdade e restrição de direitos civis, assim como, sua infraestrutura, aceitação, relacionamento dos docentes e da Escola com a Instituição carcerária, a formação dos profissionais e o contexto das práticas docentes.

A pesquisa se caracterizou como qualitativa de caráter exploratório, mediante análise documental de textos legais e de orientação, estudos bibliográficos e entrevistas semiestruturadas com os docentes que atuam na Escola em questão, possibilitando evidenciar três categorias de análise: a docência nos espaços de privação de liberdade, as práticas pedagógicas e a formação continuada dos docentes investigados. Serão analisados neste texto, elementos sobre as duas primeiras categorias.

\section{A Escola no Complexo Penitenciário de Florianópolis}

Para compreender quais as demandas de atuação e o que indicam por práticas específicas dos docentes que trabalham na Escola Supletiva da Penitenciária no âmbito da educação escolar de jovens e adultos em espaços de privação de liberdade é importante situar o contexto em que se realizou a pesquisa.

Atualmente, o programa da Secretaria de Estado da Educação de Santa Catarina (SED) é definido como Programa de Educação nas Unidades Prisionais e Unidades de Internação. Todas as unidades estão vinculadas ao Centro de Educação de Jovens e Adultos (CEJA) de cada município.

Existem diferenças políticas, estruturais e quanto ao tipo de atendimento entre as unidades prisionais e as unidades de internação, pois, enquanto a primeira é de execução penal, a segunda caracteriza-se pela 
atividade socioeducativa. A unidade prisional atende homens e mulheres apenados e a unidade de internação atende apenas aos adolescentes/jovens em cumprimento de medidas socioeducativas. A pesquisa restringiu-se a refletir sobre a educação dentro dos espaços de execução penal.

Em âmbito nacional, as taxas de encarceramento vêm aumentando de forma significativa. De acordo com Julião (2007, p. 29), concomitantemente a esse crescimento da população carcerária, está o sucateamento das instituições prisionais como um todo e consequentemente das condições mínimas adequadas para o atendimento dos/as detentos/as.

Segundo o relatório estatístico do Departamento Penitenciário Nacional (DEPEN) ${ }^{4}$, no estado de Santa Catarina, em dezembro de 2009, a população carcerária era de 13.340 internos, entre homens e mulheres, sendo 417.112 internos o número total da população carcerária no país. A população carcerária do estado corresponde a 3,2\% do país. No que se refere à idade, em Santa Catarina, a maioria dos internos - 7.908 ou $59,28 \%$ - é formada por jovens entre 18 e 29 anos. Do total dessa população carcerária, segundo os dados, 621 , ou seja, 4,65\% são analfabetos e a maioria - 5.766 ou $43,22 \%$ - não completou o Ensino Fundamental. O relatório indica que apenas 1.614 , ou $12,10 \%$, estão incluídos em atividades educacionais, as quais incluem desde a alfabetização até o ensino superior. Já em todo o país, 42.888 (10,28\%) dos internos participam de atividades educativas. Esses números ainda são pequenos, uma vez que a Lei de Execução Penal - LEP (7.210/1984) - dentre outros documentos, como a Constituição Federal e a Lei de Diretrizes e Bases da Educação (Lei 9.394/96), situam a educação como um direito de todos, independentes ou não de estarem privado de liberdade.

O Complexo Penitenciário de Florianópolis localiza-se em um bairro aparentemente de classe média, chamado Agronômica, localizada no Maciço do Morro da $\mathrm{Cruz}^{5}$, mas que em seu redor vive uma população excluída do acesso a bens culturais e sociais. Parte da população passou a ser formada por familiares dos próprios sujeitos privados ou restritos de liberdade. Já há algum tempo existem mobilizações por parte dos moradores da região para que o Complexo seja retirado desse local.

Atualmente, a Escola do Complexo funciona por meio de convênio firmado entre Secretaria Estadual de Justiça e Cidadania e Secretaria Estadual da Educação, cabendo à primeira a cessão do espaço físico e, à segunda, a cessão de professores para atuarem no Ensino Fundamental e no Ensino Médio.

O Ensino Fundamental e Médio, até o ano de 2009, realizava-se por meio de módulos fornecidos pela SED. Nas turmas de Alfabetização e Nivelamento ${ }^{6}$, o educando passa para outra turma mediante uma prova, que é realizada quando a educadora e/ou educando acham pertinentes.

Educação \& Realidade, Porto Alegre, v. 38, n. 1, p. 155-178, jan./mar. 2013.

Disponível em: <http://www.ufrgs.br/edu_realidade> 
Anualmente os alunos matriculados no ensino Fundamental e Médio da Escola da Penitenciária, prestam exames do ENCCEJA7 ${ }^{7}$, sem se deslocar das dependências do Complexo Penitenciário. Os alunos do regime semiaberto têm acesso a uma sala de informática e podem participar das Olimpíadas de Matemática das Escolas Públicas, além de terem a possibilidade de realizar o Exame Nacional do Ensino Médio (ENEM) e o vestibular da Universidade Federal de Santa Catarina.

\section{A Docência nos Espaços de Privação de Liberdade}

Nesse contexto, para aprofundar as questões relacionadas aos objetivos da pesquisa, do universo de 14 (quatorze) docentes que atuaram em 2010 na Escola Supletiva da Penitenciária, optou-se por realizar entrevista semiestruturada com 4 (quatro) deles, além de um questionário respondido por escrito, com questões que focavam suas atuações e as demandas de formação docente. Zago (2003, p. 297) pondera sobre a questão de margem de escolha do número de entrevistados, situando que essa questão se dá em função da perspectiva teórico-metodológica assumida e da pergunta que se assume responder. Assim, esta pesquisadora alerta que essa escolha está alicerçada nos ou com os critérios de seleção da amostra, a qual precisa ser representativa do objeto a ser investigado particularmente no caso da pesquisa qualitativa que pretende aprofundar. Assim, se a entrevista busca profundidade, a intenção não é produzir dados quantitativos e, portanto, as entrevistas não precisam ser numerosas. Dessa forma, a escolha desses/as quatro docentes entrevistados/as deu-se a partir dos seguintes critérios: a professora mais antiga da escola; o/a professor/a com menos tempo de serviço na escola; o professor mais novo em idade e que atua no Ensino Fundamental e Médio; o professor com maior formação acadêmica; e uma professora com menor tempo de serviço e que atua no primeiro segmento do Ensino Fundamental.

Desta forma, apresenta-se o quadro dos/as professores/as entrevistados/as ${ }^{8}$, para que seja possível visualizar o perfil deles/ as.

Quadro 1 - Perfil dos/ docentes entrevistados

\begin{tabular}{|c|c|c|c|}
\hline Professor/a & Idade & $\begin{array}{c}\text { Tempo de traba- } \\
\text { lho na escola }\end{array}$ & Formação \\
\hline Roberta & 25 & 2 anos & Graduada em Pedagogia \\
\hline Maria ${ }^{*}$ & 25 & 1 mês & Graduada em Letras \\
\hline Vinícius & 31 & 3 anos & $\begin{array}{c}\text { Graduado em História e } \\
\text { Administração. Mestrado } \\
\text { em Ciências da Linguagem e } \\
\text { Doutorando em Ciências da } \\
\text { Linguagem }\end{array}$ \\
\hline Tom & 22 & $\begin{array}{c}\text { l ano } \\
\text { incompleto }\end{array}$ & $\begin{array}{c}\text { Graduando em Ciências Bio- } \\
\text { lógicas }\end{array}$ \\
\hline Elis & 53 & 6 anos & $\begin{array}{c}\text { Graduada em Pedagogia. Espe- } \\
\text { cialista em Psicopedagogia }\end{array}$ \\
\hline
\end{tabular}

* Questionário respondido por escrito. ** Além das entrevistas e questionário com os/as professores/as também foi realizada uma entrevista semiestruturada com o diretor da Penitenciária de Florianópolis. 
Os professores, no momento da contratação, são entrevistados pela coordenação da escola. Vale lembrar que a administração do Complexo não participa do processo seletivo. Ao fim dessa etapa, os selecionados assinam um termo de compromisso junto ao Complexo Penitenciário, em que constam regras ${ }^{9}$ de segurança do estabelecimento e também de comportamento do docente dentro do Complexo. A SED/ SC, em documento para Educação Básica e Profissional (2009), indica que a seleção de professores para a Educação Carcerária deve atender aos seguintes critérios:

Continuidade do professor que desenvolveu suas atividades docentes no ano anterior, desde que tenha demonstrado condições favoráveis para continuar atuando na instituição de segurança; Habilitação na área de atuação (licenciatura plena); Comprovante de formação continuada na área e/ou em áreas afins (Segurança Pública, Violência, Direitos Humanos, ECA e outras) (Santa Catarina, 2009, p. 13).

A grande maioria dos professores é contratada em caráter temporário, assim como o coordenador da escola, o que gera rotatividade no corpo docente, tendo em vista que não há garantia de trabalho para o próximo ano. Isso é contraditório, pois os próprios professores em seus depoimentos indicam que é necessário um tempo de adaptação, entrosamento, como afirma o professor Tom: "[...] fui procurando me adaptar, depois de alguns meses eu comecei a conseguir dar aula mesmo, para eles" (Nakayama, 2011, p. 196).

Grande parte dos critérios estabelecidos nem sempre são observados para um profissional atuar como docente na Escola Supletiva da Penitenciária, como, por exemplo, o que diz respeito à formação acadêmica do docente. Alguns não possuem licenciatura plena para atuar conforme regulamentado pela SED.

Por outro lado, a contrapartida que deveria ser dada no que se refere ao adicional por periculosidade somente a partir de 2010 vem sendo cumprida. Entretanto, essa ainda não é uma realidade de todas as escolas em espaços de privação de liberdade. E, as justificativas são diversas, dentre elas, as de que:

[...] o adicional é somente para os "agentes operadores da execução penal”, excluindo os professores que atuam intramuros como tais; que são profissionais da Secretaria de Educação e não da Secretaria responsável pela execução penal, responsabilizando a Secretaria parceira pelo não pagamento (Brasil, 2010, p. 22).

Todos entrevistados afirmaram que iniciaram suas atividades na escola de certa forma, por uma necessidade de trabalho e que nenhum deles foi buscar em específico o trabalho como docente nesse espaço. A fala da professora Roberta evidencia que: “[...] na verdade é a 'precisão'. A gente precisa trabalhar, não é?” (Nakayama, 2011, p. 173).

Educação \& Realidade, Porto Alegre, v. 38, n. 1, p. 155-178, jan./mar. 2013.

Disponível em: <http://www.ufrgs.br/edu_realidade> 
A opção pela atuação em espaços de privação de liberdade, no conjunto das escolhas viáveis em um universo de possibilidades muitas vezes reduzido, constituiu como uma opção de sobrevivência e de inserção no mundo do trabalho. Apenas, o professor Vinícius, que já desenvolvia outra atividade dentro do Complexo Penitenciário, conhecia um pouco da rotina da escola e dos sujeitos. O professor Vinícius aponta:

[...] pelo salário, a carga horária me possibilitava fazer o mestrado e trabalhar e o dinheiro num primeiro momento, e num segundo momento a comparação de dar aula numa escola pública e dar aula aqui dentro, pesou bastante. Essa questão do interesse do preso, o respeito, foi um critério. É claro tem vários outros critérios, como morar próximo, talvez me adequar bem à estrutura da casa ${ }^{10}$, mas o principal foram o respeito e o interesse do detento. A maneira que ocorre essa relação do professor e aluno, para mim é o diferencial desses adolescentes (Nakayama, 2011, p. 185).

Em suas falas os docentes deixam explícito que ao iniciarem suas atividades, depararam-se com uma realidade diferenciada, que o trabalho foi um desafio, como coloca o professor Tom: "Os primeiros meses eu cheguei aqui achando que era uma coisa e foi outra, bastante diferente. Eu achava que ia poder trabalhar com jeito de uma escola regular e eu vi que não dava" (Nakayama, 2011, p. 196).

De acordo com Contreras (2002, p. 149), quando os docentes iniciam seu trabalho em uma instituição educativa, introduzem-se em uma cultura com a qual aprendem a conviver, ou seja, "[...] devem encontrar a forma de relacionar suas perspectivas e expectativas com as que a instituição possui em relação a eles". Os professores que estão inseridos nos espaços de privação de liberdade assumem as expectativas que a instituição educativa e prisional possui com relação a eles, e precisam inter-relacionar os interesses e valores da escola com os valores da instituição prisional e as contradições presentes. Nessa direção, Contreras (2002, p. 150) alerta que:

[...] necessitamos entender de que maneira os docentes podem orientar estes processos de interação entre seus interesses e valores e os conflitos que a escola [e a instituição prisional] representa, com o objetivo de entender melhor que possibilidades de reflexão crítica podem ser criadas ao pertencer a uma instituição educacional (acréscimo nosso).

Perante o quadro analisado, é possível afirmar que os professores mais antigos e até mesmo os alunos os auxiliam na constituição do ser professor em uma escola situada em uma prisão. Os professores vão, com o tempo, criando e reinventando suas metodologias de ensino:

[...] aqui tem toda uma questão de adaptação metodológica, você tem que criar uma metodologia de aula e numa escola pública você talvez só pegue a coisa enlatada assim, você pega uma metodologia pronta, você

160 Educação \& Realidade, Porto Alegre, v. 38, n. 1, p. 155-178, jan./mar. 2013 Disponível em: <http://www.ufrgs.br/edu_realidade> 
pega salas estruturadas. [...] Porque cada aula é uma discussão diferente, às vezes você pega turmas que estão super integrados assim, fazem leituras e tal. E na outra aula a mesma turma não quer ler, fica olhando pela janela, aí você tem meio que se adaptar e explorar outra forma de trabalhar a matéria, fugindo do cronograma. Então esse tempo de criar uma técnica de trabalho, um diferencial, demora sabe? [...] (Trecho do Depoimento do Professor Vinícius - Nakayama, 2011, p. 186).

O professor Tom também indicou que no mínimo alguns meses ou até um ano é o período necessário para se compreender um pouco melhor os processos educativos em espaços de privação de liberdade, a fim de criar suas estratégias metodológicas. Enfim, o professor se constitui em sua prática, estabelecendo relações com uma formação que não priorizou esse contexto.

Identifica-se a necessidade de apoio e inserção desse docente, principalmente a outras questões não relacionadas à metodologia a ser utilizada:

[...] para um profissional dar conta do que precisa dentro de uma escola na prisão, primeiro, ele precisa buscar os subsídios de todas as formas, em cursos de capacitação, em preparações psicológicas. Eu já coloquei isso pra Casa, nós temos quatro psicólogos aqui dentro, nós precisamos desse apoio [...] (Trecho do Depoimento da Professora Elis - Nakayama, 2011, p. 205).

Após iniciar seu trabalho, o professor passa a constituir as suas práticas pedagógicas no espaço de privação de liberdade. Em um primeiro momento tende a fazer tentativas, experiências, para, a partir disso, estabelecer as suas práticas.

\section{A Docência na Educação de Jovens e Adultos e as Particularidades nos Espaços de Privação de Liberdade}

Pensar a docência na Educação de Jovens e Adultos (EJA) no âmbito dos espaços de privação de liberdade exigiu olhar para o modo como outros estudiosos a compreendiam e que enfoques de análise, concepções e perspectivas para a EJA emergiram nesses estudos. Segundo Laffin (2006, p. 06), tais estudos “[...] apresentam diferentes modos de construir as temáticas em torno da constituição do ser professor em especial da Educação de Jovens e Adultos".

Ribeiro (1999, p. 02) indica a constituição de um campo de estudos e práticas de Educação de Jovens e Adultos, o que “[...] implicaria a existência de um conjunto de práticas e saberes minimamente articulados em torno de princípios, objetivos ou outros elementos comuns".

Santos (2010, p. 172) defende que "[...] cada vez mais a perspectiva da EPJA [Educação de Pessoas Jovens e Adultas], no contexto brasileiro e a necessidade de profissionais formados com conhecimentos específicos para atuar em diferentes contextos e processos de escolarização, tanto em âmbito formal quanto não-formal".

Educação \& Realidade, Porto Alegre, v. 38, n. 1, p. 155-178, jan./mar. 2013. 
A partir dessas observações, importa questionar sobre que conjunto de princípios, práticas e saberes se articulam nos estudos que tratam das especificidades da docência nos espaços escolares de privação de liberdade?

Abreu (2008), ao analisar as condições do trabalho docente em um espaço de privação de liberdade reflete que:

\begin{abstract}
Com relação aos professores, eles acreditam constituir um elo entre a cultura em geral e a cultura prisional. É importante mencionar que por mais que se esforcem para oferecer ao aluno-detento uma boa educação, as condições de trabalho não atendem suas necessidades, tendo muitas vezes que improvisar nas aulas, em virtude de que a escola-campo, em muitas oportunidades, não tem sequer o giz, muito menos, recursos didático-tecnológicos (Abreu, 2008, p. 08).
\end{abstract}

Vieira (2008, p. 06) salienta que apesar desse trabalho se dar muitas vezes em local insalubre e inconstante, esses professores atuam com satisfação, evidenciando que há "um investimento pessoal do profissional de ensino que atua nas escolas prisionais".

Silva (2004, p. 06) analisou "a organização e efetivação do trabalho das professoras em sala de aula”, em que, afirma que essas professoras:

\begin{abstract}
[...] exercem a docência de acordo com as possibilidades existentes em suas condições de trabalho, bem como dos livros didáticos de que dispõem e da sua compreensão do que deve ser a educação e, especialmente a escolarização no nível inicial. Nesse processo, vão enfrentando as situações a partir dos saberes elaborados nas experiências do dia-a-dia e como permitem a situação profissional e de trabalho (Silva, 2004, p. 06).
\end{abstract}

Fiore (2003), por sua vez, em sua dissertação, não focaliza o docente, no entanto pretende que seu trabalho seja uma contribuição aos detentos e à sociedade, buscando práticas pedagógicas que atendam as particularidades dos sujeitos e a projeto pedagógico próprio à educação de adultos.

Além de buscar a ampliação do debate sobre a Educação nestes espaços, é fundamental conhecer as necessidades dos professores que ali atuam a fim de pensar estratégias que possam melhorar as condições do trabalho docente.

Costa et al. (2010, p. 03-04) comenta que os educadores que atuam com jovens e adultos em situação de privação de liberdade, precisam pensar em uma prática norteada pelo diálogo e pela reflexão crítica sobre a prática, com base em uma perspectiva freiriana, pois particularmente:

[...] tal postura se faz mais que necessária para esses educadores que trabalham com esse público, pois precisam 
estar cientes de que é preciso lutar por uma educação emancipadora, e mais ainda, é importante destacar que a Educação sozinha não pode dar conta da realidade socioeconômica em que estão inseridos, uma vez que o problema não está localizado apenas na história individual de cada detento, mas na realidade do seu entorno social (Costa et al., 2010, p. 03-04).

Esses dois elementos - a luta por processos educativos emancipatórios e o entendimento da compreensão dos sujeitos estudantes - são elementos fundamentais ao pensarmos as práticas pedagógicas nos espaços de privação de liberdade.

Para que seja possível abordar as práticas docentes dos sujeitos da pesquisa, ou seja, "[...] como definem as ações específicas de atuação no âmbito da aula como professores de jovens e adultos" (Laffin, 2006, p. 146) em espaços escolares de privação de liberdade, é necessário situar a compreensão de práticas pedagógicas. Sacristán (1995, p. 68) afirma que é necessário alargar esse conceito, ultrapassando o domínio do espaço escolar, da metodologia e da ação dos professores, enfim, o autor apresenta a noção de "sistema de práticas educativas aninhadas".

Nesse sistema, o autor afirma uma prática educativa e de ensino, no sentido antropológico, anterior e paralela à escolaridade própria de uma determinada sociedade ou cultura, em que se desenvolvem as práticas escolares institucionais: a estrutura do sistema escolar e seu funcionamento, a organização da escola e da aula. Por fim, existem as práticas consideradas como concorrentes, por se realizarem fora do chamado sistema educativo. Nesse sentido, o trabalho do professor é condicionado pelos sistemas educativos e organizações na qual estão inseridos. Sacristán (1995, p. 72) afirma que: “[...] a imagem do professor completamente autônomo é tão irreal como crer que as suas respostas são ações meramente adaptáveis a situações herdadas".

Na fala do professor Vinícius, evidencia-se esse processo em suas dimensões marcado por normas do sistema escolar que condiciona de certa forma sua autonomia:

O CEJA, órgão a que somos subordinados, mandou a gente cortar os módulos, mudar a metodologia de avaliação e simplesmente não mandou nada para dar subsídio. Então, o professor tem que mentalizar o material, materializar e dar aula! Eles cortam os módulos, que é o material que a gente tinha, e não oferecem nada para dar aula (Nakayama, 2011, p. 187).

A partir disso, é preciso se perguntar: como pensar/analisar tais práticas na docência na Educação de Jovens e Adultos em espaços de privação de liberdade?

Na pesquisa, ao se referirem às suas práticas, os professores demonstraram compreender a diferença entre a escolarização de adultos e a de crianças. A fala da professora Roberta situa essa questão: “[...] eles já são adultos, já têm uma consciência própria, uma carga de vida, certa

Educação \& Realidade, Porto Alegre, v. 38, n. 1, p. 155-178, jan./mar. 2013. 
experiência de vida e eles chegaram até aqui, por fracasso escolar, desistência, expulsão, a gente tem vários casos" (Nakayama, 2011, p. 173).

Ao serem questionados a respeito das dificuldades, todos apontaram diversos fatores como infraestrutura precária, desde salas de aula pequenas até falta de cadernos; a rotatividade por parte dos alunos internos; a dificuldade de relacionamento com os agentes penitenciários; dentre outros, conforme o professor Tom situa:

[...] Tem muita desistência, a sala começa com vinte e termina com três, quatro. [...] A gente tem dificuldade para conseguir trazer material para eles, a própria Secretaria de Educação não disponibiliza [...] A gente precisa lidar bastante com a segurança aqui de dentro, tem bastante conflito com os agentes prisionais. Para levar material didático ou material de mídia é um pouco diferente, já é mais complicado também. Como eles não conseguem fazer pesquisa em casa, então, precisamos trazer todo o material para eles conseguirem fazer, estudar [...] (Nakayama, 2011, p. 196).

Em todos os professores entrevistados foi possível perceber uma preocupação a respeito da “[...] importância de considerar os sujeitos, a história de vida e a sua intencionalidade ao procurarem a escolarização, ao pensar a organização metodológica da aula, os critérios para a seleção dos conteúdos de ensino e as atividades" (Laffin, 2007, p. 103).

A professora Elis, por exemplo, deixa explícita essa preocupação:

[...] esse desafio de motivar, de fazer, de escolher o tema, o que nós vamos falar, qual a abrangência, aonde a gente quer chegar, isso que os motiva, para que vamos fazer isso... Só para você ter uma ideia, a gente fez papel de carta, reciclado, e esse papel foi usado pra escrever para família, e esse foi o motor, a alavanca, onde eles se motivaram para aprender e é exatamente assim que eu trabalho (Nakayama, 2011, p. 215).

Mais do que levar em consideração a história de vida desses sujeitos, é importante compreender que "o respeito à autonomia e à dignidade de cada um é um imperativo ético e não um favor que podemos ou não conceder uns aos outros" (Freire, 1996, p. 59).

Ireland (2010, p. 30) questiona sobre: qual seria uma educação socialmente relevante para os jovens e adultos privados ou restritos de seu direito de ir e vir? É necessário levar em consideração ainda que: “[...] as aprendizagens que o recluso precisa para sobreviver na prisão não são necessariamente as mesmas que precisa para se reintegrar na sociedade ao cumprir sua pena".

Na pesquisa, outro elemento que se destaca como articulador do trabalho docente é o tempo na inter-relação com o funcionamento do sistema penitenciário, como situa a professora Roberta ao falar sobre o modo como organiza e planeja suas aulas:

[...] nós temos duas horas de aula, entramos às sete e meia da manhã. Na verdade, são mais de duas horas, são duas horas e meia às vezes. Entre nove e meia e dez horas eles tiram o pessoal do sistema fechado. Esse processo é feito pelos agentes prisionais. Temos essa média de duas horas 
de aula. Você planeja suas atividades para duas horas de aula, raramente você consegue cumprir ${ }^{11}$ (Nakayama, 2011, p. 180).

De acordo Furini, Durand e Santos (2011, p. 190), para Melucci, a experiência com o tempo é algo fragmentado e existem diferentes tempos no nosso cotidiano: o tempo social, aquele relacionado à marcação do relógio, definindo a rotina; o tempo interno, aquele que define como "cada pessoa vivencia sua experiência no mundo, na vida em sociedade - aquele tempo relacionado às emoções, aos sonhos, aos projetos, às sensações, aos afetos". O tempo exterior, ou social, o qual rege nossa rotina, é uma representação culturalmente construída. No caso desta pesquisa, o tempo da aula acaba marcado pelo tempo exterior, pelas representações que são construídas na relação com os agentes penitenciários, o sistema prisional e suas normas.

A professora Roberta, ao tentar situar o que significa a educação em espaços de privação de liberdade, remete a essa relação:

[...] nosso trabalho é diferenciado por estar dentro do sistema prisional. Nós precisamos nos adaptar a algumas situações que na escola regular não encontramos, principalmente coisas assim de rotina. É diferente, por exemplo, os alunos têm outro tratamento até chegar à sala de aula, coisas que não sentimos em uma escola regular [...] acaba tornando o trabalho diferenciado. $\mathrm{O}$ acesso a eles, a leitura, é diferenciado, nós temos que nos adaptar ao sistema. O sistema é muito maior que o nosso trabalho aqui dentro. Nós temos esse respeito pela Secretaria de Segurança Pública, então temos que adaptar o nosso trabalho ao sistema (Nakayama, 2011, p. 176).

Outro aspecto a ser levado em consideração é a questão dos espaços em que se dá essa docência. Para Certeau (1998), na discussão sobre espaço e lugar, o lugar representa a ordem, o estável, enquanto que espaço seria definido como o movimento inscrito pelas pessoas dentro da ordem colocada pelo lugar, o "lugar praticado". Assim, os lugares praticados pelos docentes nesse contexto são marcados por uma composição heterogênea de grupos e também pela alternância dos estudantes, fatos que evidenciam a complexidade do trabalho desse docente e das demandas da atuação desse profissional.

Além das diferentes salas de aula em meio ao mundo das grades, o Hospital de Custódia e Tratamento Psiquiátrico é mais um dos lugares em que essa diversidade dos sujeitos e as demandas da docência se explicitam. A professora Elis, ao falar de seus alunos, destaca as especificidades dessa atuação:

Porque são alunos com necessidades especiais, eu tenho aluno autista, aluno surdo, eu tenho aluno esquizofrênico, com todo tipo de problema. [...] É um Hospital de Custódia e Tratamento Psiquiátrico. Quem são? São pessoas, são adultos que cometeram pequenos delitos, ou às vezes nem cometeram delitos, eles simplesmente foram agressivos com a família (Nakayama, 2011, p. 212).

Identifica-se nos diferentes espaços de atuação desses docentes, 
modos de olhar os sujeitos e particularidades que se constituem como complexas:

[...] e nesse processo eu entrei pra trabalhar no Hospital. Eu até em casa ficava pensando: "meu Deus, como é que eu vou dar aula no meio de cama e soro, porque eu tinha essa visão, era um hospital propriamente". [...] Eu percebi primeiro ali, uma clientela assim, muito mais difícil, muito pior do que eu pudesse ter imaginado. [...] Eles estão ali por uma medida de segurança, não podem dar uma pena para eles e aí nesse processo eles ficam de um a três anos, podendo aumentar o tempo ali dentro se eles mantiverem a agressividade e tal. E ali se consegue fazer um trabalho bom, porque quando eu começo com um aluno no início do ano, geralmente eu concluo com eles, mas ali é passo de formiga mesmo, sabe? (Trecho do Depoimento da Professora Elis - Nakayama, 2011, p. 212).

Nesse espaço, há uma continuidade nos estudos dos sujeitos, não gerando o fenômeno da rotatividade, pois o docente vai até o hospital e os estudantes permanecem mais tempo nesse espaço.

Tais dimensões são fundamentais para serem pensadas, tanto em âmbito de formação inicial de docentes como continuada, e destacam a imagem que se constrói do sujeito da escolarização nos espaços de privação de liberdade.

\section{A Relação entre Professor e Aluno e a Função da Educação Escolar em Espaços de Privação de Liberdade}

Onofre (2007, p. 12) analisa as características do sujeito privado de liberdade situando que os mesmos fazem parte da população de empobrecidos e são, certamente, produto da segregação social, da pobreza, das drogas e da perda de valores humanitários. A condição de presos os coloca na categoria de "marginais", "bandidos" na pirâmide social, em que são duplamente odiados e excluídos.

Jane Paiva (2009, p. 09-10) aborda a questão do acesso à escola na prisão, em que o interno pode ir à aula não apenas "teve a 'sorte' da matrícula", mas porque o agente penitenciário nesse dia o tirou da cela. O aluno frequenta as aulas por diversos interesses além da escolarização, seja em busca de algum material escolar, da remição da pena, ou até mesmo por diálogo com alguém que está lá no mundão ${ }^{12}$.

Onofre (2007, p. 12) afirma que a frequência às atividades escolares se justifica por diversos fatores, ou seja, "[...] buscar todas as alternativas possíveis para abreviar sua estada na unidade prisional [...]". O trabalho do professor está muito além do processo de ensino-aprendizagem, implicando na consideração as especificidades desses sujeitos. Se Laffin (2006, p. 109) já discute que a organização da EJA precisa ser constituída por práticas e tempos singulares de jovens e adultos, a educação escolar em espaços de privação de liberdade precisa ser concebida de maneira ainda mais particular. 
Ireland (2010, p. 29) afirma que impressiona o aparente caos, as tensões e interferências destes espaços. Para ele, "o aprender se torna um ato heroico”, pois são muitas as distrações e a escola está inserida no meio delas. Para aqueles que tentam estudar fora do horário das aulas, a tarefa não é nada fácil, pois tudo desafia a concentração do sujeito, a televisão, o rádio, as conversas.

Para os docentes, outro aspecto comum na maioria dos sujeitos alunos é a baixa autoestima. O professor Tom aponta essa questão: "ele já tem uma concepção dele mesmo de que não vai conseguir”. Essa visão de não valorização que os alunos fazem de si, é recorrente em sujeitos adultos em processo de escolarização de maneira geral.

No entanto, é preciso considerar que os sujeitos inseridos em espaços de privação de liberdade sofrem preconceitos e rótulos ainda maiores que os demais pela imagem que é construída socialmente nas suas relações com o mundo.

Essa relação do aluno jovem ou adulto com o saber está estreitamente pautada na relação que o mesmo tem com os outros e com seu professor para além das ações relacionadas à escolarização. A professora Roberta evidencia uma relação de cuidado e preocupação com os sujeitos: "[...] eu fiz alguns projetos durante o ano e que deram certo, tiveram um resultado muito bacana. Essa questão do agasalho, a gente levantou uma campanha no inverno, conseguimos agasalhos para eles" (Nakayama, 2011, p. 182).

Por outro lado, a professora Elis expõe certo conflito na questão da relação com seus alunos:

O papel do professor nesse espaço é servir de mediador mesmo, ele não tem que vir aqui fazer favor, ouvir história, passar a mão na cabeça deles, não! Envolvimento emocional, eu reforço, é muito prejudicial, porque faz você não atender o teu planejamento, não atender as tuas prerrogativas de vir, de trabalhar, de dar conta do teu planejamento. Mas o que tu tens que fazer primeiro, todos os dias, é lembrar-se dos teus objetivos, das tuas metas, o que eu quero alcançar, que tempo eu tenho pra isso e ter essa consciência (Nakayama, 2011, p. 213).

Parece que este cuidado pensado como uma "intencionalidade de acolhimento do sujeito para o ato de conhecimento" (Laffin, 2007, p. 116) está mais presente na fala das duas professoras entrevistadas se visualizada com a dos professores homens. Estes, pelo menos nos momentos da entrevista, focam mais nas questões pedagógicas e de relacionamento com a instituição, enquanto as professoras citam também as suas atitudes e reflexões frente às dificuldades de seus alunos.

A professora Elis, por exemplo, retrata bem essa dificuldade de conviver diariamente com a dor do outro:

É muito difícil quando você executa um trabalho desses, quando você tem consciência, porque aí você passa a conviver com os problemas de- 
les, as tuas aulas são baseadas em cima da dor, da realidade deles e é uma realidade dura, não é? (Nakayama, 2011, p. 205).

Marília Pinto de Carvalho (1999) compreende que o cuidado está associado à ideia de prestação de serviços pessoais a outros, mas também no sentido de "empatia, carinho, respeito, atenção, proteção, compaixão ou compromisso com a comunidade" (Carvalho, 1999, p. 51).

A professora Elis, ao falar de seu relacionamento com seus alunos, evidencia a necessidade de envolvimento, afeto, aspectos que já não são tão citados pelos professores: "[...] então eles precisam de muita motivação, muito afeto e o que me motiva é acreditar que isso é possível" (Nakayama, 2011, p. 213).

Por um lado, o acolhimento é fundamental, no entanto, destacase que muitas vezes, os docentes, dentro de seu espaço educacional, não conhecem aquele sujeito que cometeu delitos, crimes, e que pode ser perigoso, hostil, sendo importante observar o espaço de segurança própria, do docente, o que mostra o quanto a relação professor/aluno assume aspectos de conflitos e tensão. Mas esse risco parece ficar em uma fronteira distante do docente, imiscuído por sua tarefa relacional, mesmo quando destacam que o envolvimento afetivo pode ser prejudicial.

A própria professora Elis, destaca que "envolvimento emocional, eu reforço, é muito prejudicial, porque faz você não atender o teu planejamento, não atender as tuas prerrogativas de vir, de trabalhar, de dar conta do teu planejamento". No entanto, não destaca essa dimensão da atuação como uma situação de certo risco. Mesmo que em outra fase da sua entrevista identifique os seus estudantes do Hospital de Custódia e Tratamento Psiquiátrico como aqueles "adultos que cometeram pequenos delitos, ou às vezes nem cometeram delitos, eles simplesmente foram agressivos com a família”.

Outro elemento é a desistência das aulas pelos alunos. Os docentes apontam que vários fatores desse fenômeno nem sempre são relacionados diretamente à Escola. O professor Vinícius aponta alguns deles:

Geralmente são assuntos que não dizem respeito à escola, no geral, às vezes a mulher de um aluno o deixou, talvez a visita, fosse a única coisa que ele tinha aqui. A única relação com o exterior era a visita que, em certo momento, não está mais. Aí ele não vê mais muitos objetivos, perde o rumo, digamos assim. Às vezes um conflito entre eles, conflitos com a segurança, são dezenas de fatores (Nakayama, 2011, p. 191).

O professor Tom traz a questão da rotatividade dos alunos como um dificultador do seu trabalho: "na primeira dificuldade ele desiste [...] Então tem muita desistência, a sala começa com vinte e termina com três, quatro" (Nakayama, 2011, p. 196).

O fenômeno da rotatividade é uma constante no âmbito carcerário e ocorre por diversos motivos como progressão de regime, transferências de unidade prisional etc. Outra fala da professora Elis demonstra essa angústia no que se refere à alternância dos estudantes: 
Para nós, profissionais que estamos aqui disponíveis, que temos muitas vezes salas cheias e quinze, vinte dias depois têm dois alunos, nós não conseguimos entender isso, por que isso acontece. Perguntamos isso para eles, queremos saber, cobramos mesmo. Por que não aproveitar esse tempo em teu benefício? Por que perder essa oportunidade? O que mais você tem pra fazer? (Nakayama, 2011, p. 201).

Santos (2007, p. 98) aponta em sua pesquisa que até o início da década de 1980 a metodologia e os materiais pedagógicos utilizados pela educação escolar nos presídios eram os mesmos da rede regular de ensino e que obviamente não atendiam às necessidades desses espaços. Ou seja, era a mesma educação aplicada às crianças, embora os alunos fossem adultos. Não seria este mais um fator de aumento dos índices de rotatividade e de evasão desses estudantes?

Ao relembrar as falas dos entrevistados a respeito da dificuldade de levar materiais diferenciados, filmes entre outros, é possível relacionar com o que Goffman (2010, p. 66) chama de “atividades de distração”, nas quais estão incluídas as aulas, mas também atividades como jogos, homossexualidade, drogas e o olhar que a equipe dirigente faz das mesmas:

\begin{abstract}
Oficialmente patrocinadas ou não, sempre que essas atividades de distração se tornam muito excitantes ou contínuas, a equipe dirigente tende a fazer objeções [...] aos seus olhos, a instituição, e não algum outro tipo de entidade social incrustada na instituição deve tomar conta do internado (Goffman, 2010, p. 66).
\end{abstract}

Outro fator importante a ser considerado sobre a relação entre professor e aluno, é que os entrevistados citam como um facilitador de seu trabalho o respeito por parte de seus alunos internos. No senso comum, são frequentes os questionamentos do tipo: mas não é perigoso trabalhar lá?, eles te respeitam?, eles não brigam, não são violentos na sala de aula?. Há mais espanto ainda, quando o professor menciona que não há grades entre ele e seus alunos. Inclusive, a professora Roberta ao comentar sobre uma Escola situada em espaço de privação de liberdade de outro município do Estado, que possui grades separando alunos e professores foi questionada se seria melhor as salas da Escola Supletiva terem grades. A mesma respondeu que: "eu posso dizer com certeza que não, o que faz esse trabalho ter mais sentido é eles se envolverem mais, se responsabilizarem pelas atividades em sala de aula”.

Fica evidente que o respeito por parte dos seus alunos é um grande diferencial para o seu trabalho docente e que esse respeito não é por medo, não é algo imposto, mas sim como uma forma de valorização: "o respeito, o carinho, a valorização em si, você se sentir um profissional respeitado" (Trecho do Depoimento do Professor Vinicius - Nakayama, 2011, p. 194). Já o professor Tom parece perceber esse diferencial por estar trabalhando com adultos e não necessariamente com adultos privados ou restritos de liberdade: 
Geralmente quando o aluno entra para a escola, ele não é obrigado, ele entra por que quer, porque sentiu falta do ensino. Então ele quer ter aula, não é como na escola regular para crianças que eles ainda não têm essa maturidade, da importância da educação. Aqui eles acabam respeitando mais a gente, como professor. Eles entendem mais o nosso papel como professor e da escola (Nakayama, 2011, p. 201).

De uma maneira geral é possível afirmar que aquilo que o interno mais deseja é a liberdade, conhecida por eles como "lili". Fazem planos, cálculos, no entanto, a grande questão que assombra a maior parte deles ao se aproximar da tão sonhada liberdade é: "será que posso me sair bem lá fora?" Essa insegurança, desconhecimento e muitas vezes até mesmo desamparo por parte dos órgãos legais e até mesmo de familiares, são algumas das "razões para que os ex-internados frequentemente pensem na possibilidade de 'voltar', bem como uma razão para que um número apreciável faça exatamente isso" (Goffman, 2010, p. 67).

Já a relação dos professores com os agentes prisionais nem sempre é tranquila. Embora ambos os profissionais tenham funções educativas, a relação é tensa e mínima, normalmente apenas com cumprimentos (quando estes existem) e o que mais for estritamente necessário de ambas as partes.

Geralmente o relacionamento no sistema penitenciário do docente se restringe ao agente penitenciário, por ser ele o responsável pelo deslocamento do interno. Evidencia-se que esta função restrita ao agente penitenciário é um dos grandes problemas identificados pelos professores, visto que na maioria das vezes o agente encara a ida do interno à escola, como mais trabalho a ser realizado.

A professora Elis considera que sua dificuldade no relacionamento com o Complexo Penitenciário, de forma geral, vai além da vontade do agente penitenciário. Destaca-se aqui a questão dos direitos do interno, pois apesar de a Escola estar inserida em um espaço de privação de liberdade e a prioridade ser a segurança, é preciso considerar as atividades pedagógicas e educativas:

[...] a dificuldade está em até onde o outro pode ir, até onde a Secretaria de Segurança tem o direito de estar impedindo essas aulas, de estar interrompendo esse processo educacional, porque afinal a gente tem um calendário a cumprir e de que forma eles fazem isso, se isso está coerente com as razões, porque tudo é em nome da segurança, a gente sabe, tem consciência de que está dentro de uma penitenciária, de uma instituição penal, mas mesmo assim, o direito tem que ser preservado (Nakayama, 2011, p. 206).

Por outro lado, a professora também salienta o número insuficiente de agentes penitenciários, gerando dificuldades em toda a rotina e atividades do Complexo:

[...] porque nós que vivemos no sistema penal, nós vivemos uma falta de agentes prisionais e isso é um problema aqui dentro, reflete na educação, 
no trabalho, na saúde, em tudo... Quando você não tem muitas pessoas para fazer esse trabalho, porque ainda o sistema é bem arcaico, de pegar o "cara", tirar o cadeado, colocar nos pulsos e um por um é conduzido, abre cadeado, fecha, faz a revista [...] (Nakayama, 2011, p. 209).

Segundo o documento das Diretrizes Nacionais para a oferta de educação para jovens e adultos em situação de privação de liberdade, nos estabelecimentos penais:

Poucos são os profissionais que atuam nas escolas que compreendem e respeitam a rotina de segurança das unidades penais, que também enxergam o tênue equilíbrio emocional vivenciado cotidianamente intramuros. Muitos chegam a desqualificar a rotina de segurança e, enfaticamente, a denunciam como excessiva. Geralmente a relação entre os profissionais da escola e os da gestão prisional, principalmente da área de segurança, é bastante comprometida e tensa (Brasil, 2010, p. 17).

Nessa relação com a segurança, a disciplina e a segurança acabam ficando em primeiro plano.

A professora Elis fala ainda do diálogo como elemento imprescindível para o trabalho de ambos:

[...] eu acho que a partir do momento que a gente conseguir sentar e falar dos problemas juntos, o que cabe a cada um fazer, eu acho que fica melhor pra todo mundo. Pois, [...] se o sistema não quer tirá-los ou 'é perda de tempo' ensiná-los, não tem como você ter um resultado bom. Se não se acredita, se não se dá a oportunidade para esse interno (Nakayama, 2011, p. 219).

Normalmente, somente a coordenação da Escola tem contato com o chefe de segurança, supervisores e diretor da penitenciária. Dahmer Pereira (2006, p. 186), em sua tese aponta que:

No cotidiano, portanto, as ações de guarda e proteção dos presos se desenrolam numa via de mão dupla: ao mesmo tempo em que se depende das rotinas de vigilância (abrir e fechar cadeados, as revistas corporais e de ambientes, as escoltas) para assegurar a ordem e a segurança do ambiente, a satisfação das necessidades dos presos também vai depender da ação dos profissionais da assistência e da qualidade da relação estabelecida por eles com os inspetores penitenciários, além do investimento da administração penitenciária em políticas de trabalho, assistência e educação.

O diretor da penitenciária, ao ser questionado sobre a existência de diálogo entre professores e agentes prisionais, respondeu que: "eu nunca vi uma reunião entre os professores e os agentes penitenciários. Bem pensado... Você pode ter certeza que eu vou fazer uma reunião dessas. [...] Seria mais uma conversa, uma troca [...]". 
Talvez essa seja uma via para a mudança nas concepções dos agentes prisionais a respeito da Educação nos espaços de privação de liberdade e também nas dos docentes no que se refere ao trabalho da segurança. A professora Elis, em sua entrevista, nos traz uma fala que caracteriza bem essa diferença de pensamento entre o que ela chama de "dois times":

Porque se não passa a ser dois partidos opostos: Secretaria de Educação um time, Secretaria de Segurança, outro, não é? Quem são os bons, quem são os maus, quem de fato está trabalhando, quem está vindo aqui para fazer o quê? Quem está certo, quem está errado? (Nakayama, 2011, p. 205).

Machin (2010, p. 54) afirma que

Las instituiciones del Estado que tienen la misión de brindar educación a todos, no pueden desconocer, que las mismas existen para el cumplimiento de una responsabilidad social orientada hacia toda la sociedad y por tanto incluye a los privados de libertad.

Tais responsabilidades sociais remetem ao que os docentes indicam como a função da educação escolar em espaços de privação de liberdade.

A escola situada nestes espaços desempenha um papel diferente da escola extramuros. Ela é praticamente o único espaço para o resgate da cidadania do interno (Julião, 2007, p. 47). Ao citar o que se espera destas escolas, Santos (2007, p. 107) aponta "a valorização da autonomia do interno, a problematização de sua existência e a promoção da dignidade dos que ali comparecem, sendo propostas diferentes da operação carcerária".

Essa perspectiva de educação deve estar pautada nos valores humanos, fazendo-se cumprir a assistência educacional garantida pela Lei de Execução Penal. Está também ou pelo menos deveria estar diretamente relacionada com o trabalho. No entanto, o trabalho ainda é mais valorizado do que as práticas educativas, visto que os internos são remunerados pelas atividades laborais, além da remição da pena que não é concedida por meio dos estudos ${ }^{13}$ em todos os Estados. Em algumas instituições, é preciso que se opte entre o trabalho ou a escola. Entretanto, este não é caso do Complexo Penitenciário de Florianópolis. Segundo o diretor da Penitenciária: "quem trabalha pode estudar. Eu acho que quem trabalha deve ter o direito de ser o primeiro a entrar na escola”.

Vieira (2008, p. 34) reitera que mesmo a prisão não sendo o lugar ideal para as práticas educativas, pelas dificuldades que apresenta,

[...] desde as condições do ambiente, a falta de contato do interno durante um período de tempo considerável com a sociedade e com as transformações de toda sorte por qual essa passa, até a perda de identidade pelos sujeitos privados de liberdade e da possibilidade de executar ações roti- 
neiras, como escolher sua comida e o horário em que quer desenvolver suas atividades pessoais, é necessário que se implementem ações que transformem o espaço da prisão marcado pelo sofrimento e exclusão em local de aprendizagem e esperanças.

A professora Elis corrobora essa afirmação, enfatizando que “[...] a educação na prisão é você tentar aproveitar num curto espaço de tempo, numa situação totalmente antagônica à educação, você fazer com que alguém acredite em si novamente, no pior momento da vida dele" (Nakayama, 2011, p. 212).

A Educação dentro de um espaço de privação de liberdade é um dos principais alicerces na busca pela (re)inserção social do interno. $\mathrm{O}$ professor Vinícius evidencia esta concepção ao situar que essa:

[...] é uma escola regular que segue o mesmo molde, só que com pessoas que em algum momento da vida fizeram alguma coisa errada e que estão se reeducando. Então entendo, como fazendo parte desse processo de reinserção social. Por que tipo, ressocialização, não é espancamento e humilhação, é você possibilitar condições desse indivíduo retornar à sociedade. Então talvez tudo que acontece dentro do sistema prisional, a escola é a coisa que mais cumpre esse papel de ressocializar no meu ponto de vista (Nakayama, 2011, p. 195).

Para o interno, escola é um lugar onde há a possibilidade de interação, de cooperação e principalmente de respeito mútuo e que, em seu limite, auxilia a tornar a pena menos dolorida.

É preciso compreender que a educação escolar nos espaços de privação de liberdade não pode ser vista como a redentora do aluno interno, mas, na lógica do direito subjetivo"14: "[...] eles têm o mesmo direito de estudar como qualquer outro e eles precisam exercer esse direito, eles precisam disso. É uma segunda chance... Uma segunda chance para eles" (Trecho do Depoimento do Professor Tom - Nakayama, 2011, p. 201).

A garantia do direito significa que a educação em espaços de privação de liberdade não é uma regalia, é o exercício de um direito. Entretanto, são poucos os que têm conhecimento acerca desse direito subjetivo. É também papel da escola inserida nos espaços de privação de liberdade, conscientizar os internos destes direitos e, principalmente, de orientá-los no sentido de exigir o cumprimento dos mesmos.

A professora Elis afirma que para existir de fato suporte na (re)inserção social do interno, há a necessidade de um trabalho em conjunto:

A educação na prisão deveria ser um trabalho feito assim... Em tempo maior, deveria ser um trabalho coletivo, não só com a educação, mas de fato com o social, com a psicologia, com a segurança, porque todos deveriam ter um único objetivo. Diminuir o índice de reincidência, que é alto demais, não é? De que forma a gente poderia fazer isso? Todos fazerem a mesma força e não forças contrárias, não um cabo de guerra [...] (Nakayama, 2011, p. 218).

Educação \& Realidade, Porto Alegre, v. 38, n. 1, p. 155-178, jan./mar. 2013.

Disponível em: <http://www.ufrgs.br/edu_realidade> 
Nesse contexto, um trabalho multidisciplinar, durante o processo educativo e principalmente um acompanhamento do egresso pode fazer toda a diferença na (re)inserção social do sujeito. No entanto, para esse trabalho em colaboração é fundamental pensar processo formativos para os diferentes profissionais que atuam como agentes educativos.

\section{Algumas Considerações}

A educação em espaços de privação e restrição de liberdade não deve ser situada pelos mesmos princípios da Educação de Jovens e Adultos que se desenvolve em outros espaços, sendo necessário observar as particularidades, diferenças, características e contextos.

A EJA geralmente trabalha com o sujeito trabalhador, com um sujeito com o direito de ir e vir, com aquele que faz escolhas, ali são outras condições de vida. É preciso lidar com a privação desse 'ir e vir', do trabalho, da família, do lazer e até do saber. Para isso, é preciso lidar com seus saberes prévios, suas experiências de vida, anteriores e aquelas construídas após sua inserção nesse espaço, suas expectativas e, principalmente, aqueles saberes que podem ser relevantes e significativos para o sujeito da situação de privação e restrição de liberdade, no sentido de contribuir para (re)inserção social. Tal dinâmica só poderá ser possível mediante uma perspectiva dialógica e relacional a ser construída no trabalho docente, para o qual, conforme dados desta pesquisa, os docentes ainda não obtiveram formação para tal.

O professor se constitui em sua prática estabelecendo relações com a formação inicial, a qual não priorizou o contexto de privação de liberdade. Nesse sentido, uma das questões que se evidenciou nesse espaço foi reconhecer na ação pedagógica o aluno interno e suas especificidades, assim como suas experiências de vida, seu histórico como fatores fundamentais para o trabalho docente pelos professores. Vêm de históricos de insucesso escolar e da percepção de baixa autoestima. São sujeitos marcados pelo preconceito e pelos rótulos de 'bandidos', 'vagabundos', 'marginais', mas que na sala de aula precisam ser reconhecidos como sujeitos em busca de construção de identidade e de saberes.

Já com relação ao papel do professor e ao trabalho docente nos espaços de privação e restrição de liberdade, os professores entrevistados situam como um papel de mediador de saberes em que as relações, seja com os alunos seja com os agentes penitenciários, estão sempre presentes. 


\section{Notas}

1 Ao analisar as necessidades de educação continuada situa-se que segundo Rodrigues e Esteves (1993, p. 19) o termo "necessidade", de acordo com a Psicologia, é caracterizada pela ambiguidade, que pode designar fenômenos diferentes como uma vontade, desejo, um precisar de algo ou ainda uma exigência. Pode remeter tanto à ideia do que tem de ser, do que é imprescindível ou inevitável, tanto como uma forma mais subjetiva, em que o sujeito não está tão determinado pela necessidade, neste caso a necessidade não existe, senão pelo sujeito que a sente. As autoras ainda afirmam que não se pode falar de necessidades absolutas e que estas sempre estão relacionadas aos sujeitos e contextos e estão diretamente relacionadas aos valores, pressupostos e crenças dos mesmos. Entretanto, algumas necessidades podem ser sentidas ou percebidas por um número grande de sujeitos, o que lhes confere força coletiva. Para mais informações ver: RODRIGUES, Angela. ESTEVES, Manuela. A Análise de Necessidades na Formação de Professores. Porto Editora: Porto, Portugal, 1993.

2 Embora não seja objeto de análise a questão da formação continuada de docentes, registra-se que a concepção da pesquisa realizada entende-se essa questão como diretamente articulada à formação inicial do profissional, com dimensões diferentes, porém que constituem o mesmo processo de aprendizagem e profissionalização. No que se refere à utilização do termo mais apropriado, entre formação ou educação continuada ou ainda educação permanente, compreendemos assim como Laffin (2006, p.15), que estes termos “[...] podem ser apresentados em um mesmo bloco, pela sua proximidade e por tomarem como eixo o conhecimento, a ideia de processo como percurso". Ao abordar a educação continuada, diferentes terminologias e concepções são utilizadas para mencionar o processo de formação que se estende além da formação inicial. Marin (1995, p.18) aponta as concepções, possíveis influências e críticas à utilização de cada um destes termos, e na pesquisa optamos pelos termos educação permanente, formação ou educação continuada por estarem inseridos no mesmo bloco, devido às suas similaridades. Contudo, a autora ainda traz algumas diferenciações: a concepção de educação permanente nos remete à “[...] educação como processo prolongado pela vida toda, em contínuo desenvolvimento". Assim, a formação continuada "[...] guarda o significado fundamental de atividade consciente proposta, direcionada para a mudança.” Já educação continuada, para a autora, pode ser utilizada de forma mais ampla, na medida em que pode incorporar as noções citadas anteriormente e ainda tem a significação fundamental do conceito de que a "educação consiste em auxiliar profissionais a participar ativamente do mundo que os cerca, incorporando tal vivência no conjunto dos saberes de sua profissão." Para mais detalhes ver: MARIN, Alda Junqueira. Educação continuada: introdução a uma análise de termos e concepções. In: Cadernos CEDES, Campinas, 1. ed. 1995.

3 Apesar de hoje já não se utilizar mais o termo supletivo, esta palavra ainda está presente no nome da Escola. Outro aspecto que cabe ressaltar é que o nome é Escola Supletiva da Penitenciária e não do Complexo Penitenciário. O nome se manteve com o passar dos anos.

4 Em 2004, o Departamento Penitenciário Nacional (DEPEN) criou o Sistema de Informações Penitenciárias, o InfoPen, um programa de coleta de dados, alimentado pelas secretarias estaduais, com informações estratégicas sobre $o$ sistema prisional como um todo. Disponível em: <http://portal.mj.gov.br/depen/ data/Pages/MJC4D50EDBPTBRNN.htm>. Acesso em: 05 mar. 2011.

Educação \& Realidade, Porto Alegre, v. 38, n. 1, p. 155-178, jan./mar. 2013. 
5 Localizada na região central do município de Florianópolis, residem na região, cerca de 22.500 habitantes. Fonte: Prefeitura Municipal de Florianópolis. Disponível em: <http://www.pmf.sc.gov.br/entidades/habitacao/index.php?cm $\mathrm{s}=$ projeto+macico+do+morro+da+cruz\&menu=8>. Acesso em: 05 mar. 2011.

6 As turmas de nivelamento são aquelas que possuem educandos já alfabetizados e prosseguirão no Ensino Fundamental. Esta nomenclatura é utilizada pelos CEJAs - Centro de Educação de Jovens e Adultos, mantidos pela SED.

7 ENCCEJA - Exame Nacional para Certificação de Competências de Jovens e Adultos é realizado pelo INEP - Instituto Nacional de Estudos e Pesquisas Educacionais Anísio Teixeira.

8 Os nomes dos docentes são fictícios para preservar a identidade dos mesmos.

9 Entre essas regras, algumas estão relacionadas ao vestuário dos professores, a proibição de entrar em sala de aula com objetos cortantes e pontiagudos, bolsa, isqueiro, celular, prestar favores (transmissão de recados, telefonemas, envio de cartas), encaminhamento direto de roupas, calçados, cobertores, entre outros.

10 Quando o entrevistado utiliza o termo "casa", o mesmo está se referindo ao Complexo Penitenciário de maneira geral, seja a estrutura física ou mesmo à Direção e seus colaboradores.

11 A professora Roberta está se referindo apenas ao regime fechado. A duração das aulas varia de acordo com o local.

12 Expressão bastante utilizada pelos internos na época em que atuei como docente na Escola Supletiva da Penitenciária.

13 Em Santa Catarina, a remição da pena pelos estudos já foi aprovada e significa que a cada três dias de aula é diminuído um dia de sua pena.

14 É aquele em que “[...] é necessária a expressão do sujeito de querer valer-se dele para sua efetivação” (Sartori, 2011 p. 43). Para aprofundamento consultar: SARTORI, Anderson. Legislação, Políticas Públicas e Concepções de Educação de Jovens e Adultos. In: LAFFIN, Maria Hermínia Lage Fernandes (Org.). Educação de Jovens e Adultos e educação na diversidade. Florianópolis: Universidade Federal de Santa Catarina, 2011.

\section{Referências}

ABREU, Almiro Alves de. Educação entre Grades: um estudo sobre a educação penitenciária do Amapá. 2008. 130 f. Dissertação (Mestrado em Educação) - Programa de Pós-Graduação em Educação, Universidade Federal de São Carlos, São Carlos, São Paulo, 2008.

BRASIL. Conselho Nacional de Educação. Diretrizes Nacionais para a Oferta de Educação para Jovens e Adultos em Situação de Privação de Liberdade. Parecer n. 04 de 9 de março de 2010. Brasília, 2010.

BRASIL. Conselho Nacional de Educação. Dispõe sobre as Diretrizes Nacionais para a Oferta de Educação nos Estabelecimentos Penais. Resolução n. 03 de 11 de março de 2009. Disponível em: <http://portal.mec.gov.br/index. php?option=com_content\&view=article\&id=12992:diretrizes-para-a-educacaobasica\&catid=323:orgaos-vinculados $>$. Acesso em: 17 abr. 2010.

CARVALHO, Marília Pinto de. No Coração da Sala de Aula: gênero e trabalho docente nas séries iniciais. São Paulo: Xamã, 1999. 
CERTEAU, Michel de. A Invenção do Cotidiano: as artes do fazer. Petrópolis: Vozes, 1998.

CONTRERAS, Jose. A Autonomia de Professores. São Paulo: Cortez, 2002.

COSTA, Francisco Xavier Santos, et. al. Educação em Espaços de Privação de Liberdade: considerações acerca do Parecer CNE/CEB nº 4/2010. In: I CONGRESSO INTERNACIONAL DA CÁTEDRA UNESCO DE EDUCAÇÃO DE JOVENS E ADULTOS. 2010. João Pessoa. Anais... 2010. V. 1. P. 01-15.

FIORE, Miriam Rodrigues. A Educação na Penitenciária Feminina da Capital: a crença na reabilitação. 2003. 131 f. Dissertação (Mestrado em Educação, Administração e Comunicação) - Programa de Pós-Graduação em Educação, Universidade de São Marcos, São Marcos, São Paulo, 2003.

FREIRE, Paulo. Pedagogia da Autonomia: saberes necessários à prática educativa. São Paulo: Paz e Terra, 1996.

FURINI, Dóris Regina Marroni; DURAND, Olga Celestina da Silva; SANTOS, Pollyana dos. Sujeitos da Educação de Jovens e Adultos, Espaços e Múltiplos Saberes. In: LAFFIN, Maria Hermínia Lage Fernandes (Org.). Educação de Jovens e Adultos e Educação na Diversidade. Florianópolis: Universidade Federal de Santa Catarina, 2011. P. 160-245.

GOFFMAN, Erving. Manicômios, Prisões e Conventos. São Paulo: Perspectiva, 2010.

IRELAND, Timothy. Anotações sobre a Educação em Prisões: direito, contradições e desafios. In: CRAIDY, Carmen Maria. Educação em Prisões: direito e desafio. Porto Alegre: Editora da UFRGS, 2010. P. 23-36.

JULIÃO, Elionaldo Fernandes. As Políticas de Educação para o Sistema Penitenciário. In: ONOFRE, Elenice Maria Cammarosano (Org.). Educação Escolar entre as Grades. São Carlos: EdUFSCar, 2007. P. 29-50.

LAFFIN, Maria Hermínia Lage Fernandes. Reciprocidades e Acolhimento na Educação de Jovens e Adultos: ações intencionais na relação com o saber. Revista Educar, Curitiba, Editora UFPR, n. 29, p. 101-119, 2007.

LAFFIN, Maria Hermínia Lage Fernandes. A Constituição da Docência entre Professores de Escolarização Inicial de Jovens e Adultos. 2006. 216 f. Tese (Doutorado em Educação) - Programa de Pós-Graduação em Educação, Universidade Federal de Santa Catarina, Florianópolis, Santa Catarina, 2006.

MACHIN, Felipe. Condiciones que Deberían Estar Presentes para una Mejor Intervención Educativa en las Prisiones. In: CRAIDY, Carmen Maria. Educação em Prisões: direito e desafio. Porto Alegre: Editora da UFRGS, 2010. P. 56-57.

NAKAYAMA, Andréa Rettig. O Trabalho de Professores/as em um Espaço de Privação de Liberdade. 2011. 226 f. Dissertação (Mestrado em Educação) - Programa de Pós-Graduação em Educação, Universidade Federal de Santa Catarina, Florianópolis, Santa Catarina, 2011.

ONOFRE, Elenice Maria Cammarosano. Escola da Prisão: espaço de construção do homem aprisionado. In: ONOFRE, Elenice Maria Cammarosano (Org.). Educação Escolar entre as Grades. São Carlos: EdUFSCar, 2007. P. 11-28.

PAIVA, Jane. Estudantes Internos Penitenciários. In: AGUIAR. Maria Ângela da Silva. (Org.). Educação de Jovens e Adultos: o que dizem as pesquisas. Recife: Gráfica J. Luiz Vasconcelos, 2009. P. 09-36.

PEREIRA, Tânia Maria Dahmer. O Guarda Espera um Tempo Bom: a relação de custódia e o ofício dos inspetores penitenciários. 2006. $365 \mathrm{f}$. Tese (Doutorado em Serviço Social) - Programa de Pós-Graduação em Serviço Social, Universidade Federal do Rio de Janeiro, Rio de Janeiro, Rio de Janeiro, 2006.

Educação \& Realidade, Porto Alegre, v. 38, n. 1, p. 155-178, jan./mar. 2013.

Disponível em: <http://www.ufrgs.br/edu_realidade> 
O Trabalho de Professores/as em Um Espaço de Privação de Liberdade

RIBEIRO, Vera Maria Masagão. A Formação de Educadores e a Constituição da Educação de Jovens e Adultos como Campo Pedagógico. Educação \& Sociedade, Campinas, n. 68, p. 184-201, dez. 1999.

SACRISTÁN, Gimeno. Consciência e Acção sobre a Prática como Libertação Profissional dos Professores. In: NÓVOA, A. (Org.). Profissão Professor. Porto Editora: Porto, Portugal, 1995. P. 63-92.

SANTA Catarina. Diretoria de Educação Básica e Profissional. Documento Normativo Educação Básica e Profissional - 2009. Florianópolis, 2009.

SANTOS, José Jackson Reis dos. Especificidades dos Saberes para a Docência na Educação de Pessoas Jovens e Adultas. Práxis Educacional, Vitória da Conquista/ES, v. 6, n. 8, p. 157-176, jan./jun. 2010. Disponível em: <http://periodicos.uesb. br/index.php/praxis/article/viewFile/292/325>. Acesso em: 01 set. 2011.

SANTOS, Sílvio dos. A Educação Escolar na Prisão sob a Ótica dos Detentos. In: ONOFRE, Elenice Maria Cammarosano (Org.). Educação Escolar entre as Grades. São Carlos: EdUFSCar, 2007. P. 93-110.

SARTORI, Anderson. Legislação, Políticas Públicas e Concepções de Educação de Jovens e Adultos. In: LAFFIN, Maria Hermínia Lage Fernandes (Org.). Educação de Jovens e Adultos e Educação na Diversidade. Florianópolis: Universidade Federal de Santa Catarina, 2011.

SILVA, Maria da Conceição Valença da. A Prática Docente da EJA: o caso da Penitenciária Juiz Plácido de Souza em Caruaru. 2004. 274 f. Dissertação (Mestrado em Educação) - Programa de Pós-Graduação em Educação, Universidade Federal de Pernambuco, Recife, Pernanbuco, 2004.

VIEIRA, Elizabeth de Lima Gil. Trabalho Docente: de portas abertas para o cotidiano de uma escola prisional. 2008. 137 f. Dissertação (Mestrado em Educação) - Programa de Pós-Graduação em Educação, Pontifícia Universidade Católica do Rio de Janeiro. Rio de Janeiro, Rio de Janeiro, 2008.

ZANIN, Joslene Eidam. Direito a Educação: políticas públicas para a ressocialização através da educação carcerária na penitenciária estadual de Ponta Grossa. 2008. 92 f. Dissertação (Mestrado em Educação) - Programa de Pós-Graduação em Educação, Universidade Estadual de Ponta Grossa, Ponta Grossa, Minas Gerais, 2008.

Maria Hermínia Lage Fernandes Laffin é professora adjunto da Universidade Federal de Santa Catarina, em Florianópolis, Santa Catarina. Tem experiência na área de Educação, com ênfase em Didática e Educação de Jovens e Adultos pesquisando principalmente nos seguintes temas: Educação de Jovens e Adultos, formação de professores, educação, escolarização e práticas escolares. País: Brasil - Santa Catarina/ Florianópolis.

E-mail: herminialaffin@gmail.com

Andréa Rettig Nakayama é mestre em Educação pela Universidade Federal de Santa Catarina, em Florianópolis, Santa Catarina. Professora do Ensino Regular Básico de Santa Catarina. Especialista em Educação para jovens e adultos em situação de privação de liberdade. País: Brasil - Santa Catarina/ Florianópolis.

E-mail: dea.naka@gmail.com 